\title{
Values in Design - Building Bridges between RE, HCI and Ethics*
}

\author{
Christian Detweiler ${ }^{1}$, Alina Pommeranz ${ }^{1}$, \\ Jeroen v.d. Hoven ${ }^{1}$, and Helen Nissenbaum ${ }^{2}$ \\ ${ }^{1}$ Delft University of Technology, The Netherlands \\ \{c.a.detweiler, a.pommeranz,m.j.vandenhoven\}@tudelft.nl \\ ${ }^{2}$ New York University, USA \\ helen.nissenbaumenyu.edu
}

\section{Objectives}

Designing for values has become increasingly important for technology development. In many technological systems (medical applications, social networks etc.) values (privacy, autonomy, trust etc.) play a role and are sometimes violated. In working with stakeholder requirements or user needs, various design methods in requirements engineering (RE) [3] and human computer interaction (HCI), in specific user-centered (UCD), deal with "soft issues" [4], "social issues", "people issues" or values. At the same time, applied ethics has begun to pay attention to design. We believe that many of the approaches could complement each other in useful ways. The aim of this workshop is to bring together people from different disciplines to share knowledge and insights about how to account for values in technology design, and to work towards integrating approaches, thereby putting value conscious design approaches (e.g. values-in-design [1] or value sensitive design [2]) to practice.

\section{Theme and Topics}

The main theme is the interdisciplinary exchange of knowledge, experiences and new ideas on values in technology design. The following list reflects possible topics:

- Designing for specific values, experiences from value-oriented projects

- Understanding and relating different notions of values

- Integrating value-oriented methods with software engineering/ design methods

- Accounting for values in experience oriented designs, e.g. "fun" as a value

- Values used in evaluations of User Experience (UX)

- Dealing with soft issues, social issues, and people issues in RE, Value-based RE

- Value elicitation, dealing with a variety of stakeholder values

- Capturing and reusing value knowledge (scenarios, design patterns, etc.)

- Values in Persuasive Technology, Ambient Intelligence and Personal Informatics

- Values in specific domains (health care, military, crisis management)

* All authors of this proposal are to be considered key organizers of the workshop. 
The target audience includes HCI and social science researchers interested in social aspects of technology and values in design. We also aim at researchers focusing on soft issues in RE, UCD and moral philosophers interested in ethics and technology. For interactions between academia and industry we will invite (interaction) designers and software engineers/developers.

\section{Workshop Format}

This is a one-day workshop divided into two parts. In the first half we will have four consecutive panel sessions: the values turn in design - "soft issues" in RE and UCD; the design turn in applied ethics; values across disciplines; and values in industry. Panels will be led by representatives in the respective field. Each panel will be initiated by short presentations by authors of accepted papers followed by a discussion with all workshop participants. In the second part, we will create groups of 4-5 participants with different backgrounds (RE, HCI and Ethics). Each group will be given a design case to work on using tools and methods proposed by the participants. The aim will be to create an overview of people issues, values, soft issues and (long term) social aspects emerging from each design case. In a debriefing session we will share experiences (regarding the cases and tools used) from the group work with all participants. Participants who wish to present their work as posters or demos will be given the opportunity to do so during the breaks.

\section{Expected Outcomes}

We expect that the interdisciplinary collaboration in the workshop will lead to new ideas and more practical approaches to the inclusion of values in technology design. More specifically, an outcome of the workshop will be the publication of a volume of extended versions of work submitted to the workshop highlighting the state of the art in addressing values in design. Additionally, insights from the panel discussions and interdisciplinary work will form the basis for a number of publications in a special issue of the "Ethics and Information Technology" journal focusing combining existing approaches, and on new approaches that emerge from the workshop.

\section{References}

1. Flanagan, M., Howe, D., Nissenbaum, H.: Embodying Values in Technology: Theory and Practice. In: van den Hoven, J., Weckert, J. (eds.) Information Technology and Moral Philosophy. Cambridge University Press, Cambridge (2008)

2. Friedman, B., Kahn, P., Borning, A.: Value Sensitive Design and Information Systems. In: Zhang, P., Galletta, D. (eds.) Human-Computer Interaction and Management Information Systems: Foundations, pp. 348-372. M.E. Sharpe, New York (2006)

3. Proynova, R., Paech, B., Wicht, A., Wetter, T.: Use of personal values in requirements engineering - A research preview. In: Wieringa, R., Persson, A. (eds.) REFSQ 2010. LNCS, vol. 6182, pp. 17-22. Springer, Heidelberg (2010)

4. Thew, S., Sutcliffe, A.: Investigating the Role of 'Soft Issues' in the RE Process. In: 16th IEEE International Requirements Engineering, RE 2008, September 8-12, pp. $63-66$ (2008) 